\title{
Catálogo de la colección de bienes muebles Fundación Casa Medina Sidonia
}

\section{Sevilla: Consejería de Fomento y Vivienda, 2018}

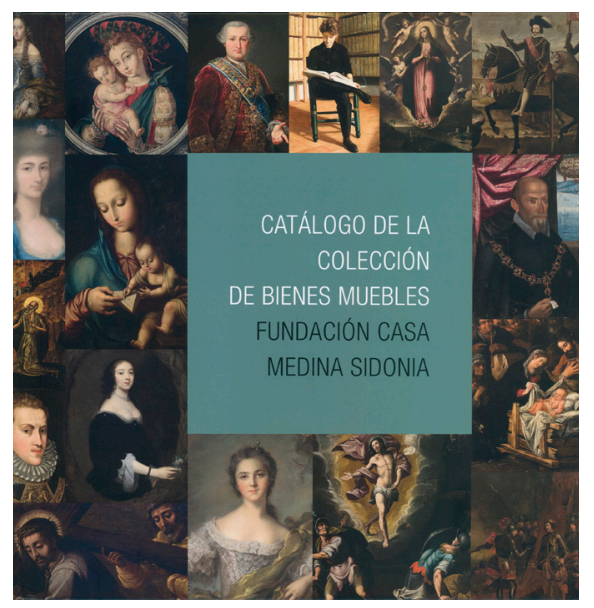

Desde 1990 la Fundación Casa Medina Sidonia conserva y difunde el rico acervo cultural que custodia el Palacio de los Guzmán en Sanlúcar de Barrameda, puesto al servicio de la sociedad por expresa voluntad de la duquesa Luisa Isabel Álvarez de Toledo (1936-2008), instigadora de la Fundación y a cuya instancia el inmueble y sus contenidos fueron declarados Bien de Interés Cultural en 1978 para evitar así su dispersión.

La trascendencia de dicho patrimonio bien justifica el interés de la Junta de Andalucía por contribuir a su estudio y puesta en valor. Los primeros esfuerzos de colaboración, que se remontan a 2006, se centraron en el inmenso Archivo Histórico -uno de los más importantes archivos privados de Europay tienen vocación de continuidad: acaba de comenzar la digitalización del legado documental que facilitará el acceso libre a sus más de 6.000 legajos.

En este marco de cooperación institucional público-privada para la democratización de la cultura se encuadra el Catálogo de la Colección de Bienes Muebles. Fundación Casa Medina Sidonia. Presentado en enero de 2019, se dirige al conjunto de la ciudadanía y muy en particular a los investigadores, a cuyo alcance pone una selección de 110 obras fechadas entre los siglos XVI y XX. Principalmente se trata de pintura y escultura, pero no faltan ejemplares notables de mobiliario, cerámica, textiles, relojes, metalistería y grabado, agrupándose las piezas por tipologías.

El análisis crítico ha corrido a cargo de un equipo de especialistas coordinado por el Instituto Andaluz de Patrimonio Histórico, en el que interviene puntualmente Liliane Dahlmann, presidenta de la Fundación. La contextualización de los asuntos iconográficos, tipos y técnicas es sin duda el punto fuerte de la catalogación, que en no pocos casos sirve para compensar la escasez de datos registrados en torno al origen de los bienes. Coadyuva en este sentido la inclusión de un elevado número de reproducciones de piezas pertenecientes a colecciones de todo el mundo, que fundamentan las atribuciones y apoyan las conclusiones alcanzadas en la clasificación razonada.

Buena parte del catálogo está dedicado al conjunto de las obras provenientes de la iglesia del convento de Nuestra Señora de la Merced de Sanlúcar, cuyo patronazgo ejercieron los duques. Sobresalen por su abundancia y calidad los lienzos ejecutados por Juan de Roelas para la decoración del templo, pero tampoco conviene olvidar los frontales de altar cerámico o la pintura de la Inmaculada, atribuidos respectivamente a Hernando de Valladares y al Caballero de Arpino. 
Con igual rigor se han abordado otras obras como el lienzo asignado a Luis de Morales, los tapices de François van den Hecke, las arcas y bargueños europeos y españoles, las esculturas devocionales o la terna de retratos de doña Luisa Isabel, apreciables, más allá de otros méritos, porque según la duquesa representaban sucesivamente: "lo que querían que fuera, en lo que me convirtieron" y, por fin, "lo que quería ser".

Como crítica menor, dentro de cada tipología se echa en falta el empleo de criterios objetivos de ordenación, como podría haber sido la cronología, la escuela o incluso la ubicación de los bienes en el interior del palacio. La ordenación, por tanto, se antoja arbitraria.

No obstante, por encima de todo es digna de aprecio la contribución del Catálogo al conocimiento científico del patrimonio andaluz, que garantiza oportunamente su proyección y disfrute. En último lugar, celebramos que el escollo a la difusión que podría haber supuesto el precio o el limitado número de ejemplares impresos se haya salvado, acertadamente, a través de su publicación como libro electrónico en la web de la Consejería de Fomento de la Junta de Andalucía.

Leticia García de Ceca Sánchez del Corral | gestora cultural

URL de la contribución <www.iaph.es/revistaph/index.php/revistaph/article/view/4632> 